\title{
Quality Improvement of Green Table Olive cv. 'Domat' (Olea europaea L.) Grown in Turkey Using Different De-Bittering Methods
}

\author{
ElifSAVAȘ ${ }^{1}$ Vildan UYLAȘER ${ }^{*}$ \\ ${ }^{1}$ University of Uludag, Institute of Science, Bursa, Turkey \\ ${ }^{2}$ University of Uludag, Faculty of Agriculture, Department of Food Engineering, Bursa, Turkey; uylaserv@uludag.edu.tr ( ${ }^{*}$ corresponding author)
}

\begin{abstract}
The most basic step in table olive production is de-bittering. Olives contain bitter flavor compounds such as oleuropein, and their presence precludes the consumption of fresh fruits. Oleuropein can be removed by natural methods (e.g., using tap water) or by applying various chemicals (e.g., lye). Chemicals affect the organoleptic and nutritional qualities of the olive fruit. The aim of this study was to improve the quality of naturally fermented 'Domat' cultivar green table olives using different de-bittering methods (by scratching, using $1 \%$ lye and using tap water). The lye pre-treatment negatively affected the nutritional, organoleptic and color qualities of the olives. In all of applications, the best color stability was obtained in the olives that were de-bittered using the scratching method.
\end{abstract}

Keywords: de-bittering, fermentation, green olive, oleuropein, quality

\section{Introduction}

Olives are part of Turkish culture. Historically, it has been reported that wild olive trees originated from Asia Minor and likely spread from Syria to Greece via Anatolia. A significant amount of olive production occurs in the region around the Mediterranean coast. The olive business plays an important role in the Turkish economy. In Turkey, table olive consumption is higher than olive oil consumption.

Table olives are the most important fermented food worldwide. In the 2010-2011 season, world table olive production reached 2,369,000 tons, the majority of which (48\%) was produced in the European Union, particularly in Spain, Italy, Greece (809,000 tons) and Turkey (330,000 tons). Clearly, Turkey is one of the most important countries for table olive production. Other countries that produce significant amounts of olives include Argentina (10.5\% of world production), Egypt (8.4\%), the US (6.5\%), Syria (5.9\%) and Morocco (4.6\%). World consumption has reached 2.205.000 tons, and the European Union is the major consumer $(26 \%, 574,000$ tons) followed by Turkey (1.8\%, 260,000 tons), the USA (10.9\%, 240,000 tons), Egypt (17\%, 190,000 tons) and Algeria (5.8\%, 129,000 tons) (IOOC, 2012). Currently, there are four main types of table olives: Spanish-style green olives, Gemlik-style or Greek-style naturally black olives, Californian-style ripe olives and dry salted-style olives. Gemlik or the Greek-style olives are popular in Turkey, Greece and Northern African countries. Turkey is the largest producer of this type of olive (24-27\%), followed by Greece (1821\%) (Piga et al., 2001; Romero et al., 2004; Uylaser et al.,
2008). Production methods, which vary based on table olive cultivar, differ considerably from region to region. The 'Domat' cultivar is cultivated mainly in the Agean Region of Turkey. This cultivar is used in the production of green table olive by the traditional scratching method.

Consuming an adequate and balanced diet is one of the most important health goals. Research studies on nutrition related health problems have directed attention to the eating habits of individuals in different regions and countries; this attention has led to the creation of definitions such as the "Mediterranean diet". Table olives and olive oil are the most representative foods in the traditional Mediterranean diet. A common component of the Mediterranean diet is biophenols. Biophenols, which constitute the largest group of secondary plant metabolites, are universally present in plants and are recognized for their health benefits. There are more than 100 different biophenols in olive products (e.g., fruit, oil, leaves and waste). The biophenol composition differs among the various olive products (fruit, oil, leaves and waste) and tissues (pulp and stone). Major biophenols, including hydroxytyrosol, tyrosol and their secoiridoid derivatives (e.g., oleuropein, oleuropein aglycone and elenolic acid dialdehydes), verbascoside, lignans (acetoxypinoresinol), and flavonoids (rutin and glycosides of luteolin and apigenin), have been detected in olive products (Ghanbari et al., 2012; Obied et al., 2007, 2012; Servili et al., 2004).

Biophenols, which have health benefits and are important for green table olive fermentation, are responsible for bitterness in the olives. Olive fruits contain oleuropein, which is an alkaloid that contributes to a bitter unpalatable taste. For this reason, olive fruits cannot be directly 
270

consumed from the tree and must undergo a series of processes that differ considerably from region to region and depend on the olive variety. However some olive varieties (e.g., the Thrubolea variety grown in Greece) are an exception to this rule because, as they ripen in the tree, they become sweeter, in most cases, this increase in sweetness is due to fermentation. The bitter constituents (oleuropein) in olive fruits are reduced by lye treatment in the processing of green olives and California-style ripe olives. Ripe olives, on the other hand, can be directly preserved in salt or brine (Garrido Fernández et al., 1997; Rodriquez-Gomez et al., 2012; Uylaser et al., 2008). During the removal of bitter compounds via lye treatment, various flavor substances are leached out of the fruit and into the water and contribute to the soapy aroma of fermented olives. In addition to changing sensory factors, lye treatment decreases the initial acidity of the brine.

Lye treatment facilitates olive production but reduces the naturalness of the product and contributes to environmental pollution due to the associated waste. In recent years, the use of natural methods in the cultivation and processing of foods has resulted in changes in the olive market. For this reason, attention has been focused on the traditional food processing methods that do not involve chemicals. The aim of this study was to investigate the effects of different de-bittering methods, including the scratching method, which has been a traditional practice in Turkey, on the quality of 'Domat' cultivar green table olives.

The results derived from this study will be useful in the desing of new processes that can be applied in the olive production industry.

\section{Materials and methods}

\section{Materials}

A total of approximately $21.5 \mathrm{~kg}$ lots of 'Domat' cultivar olives with an average weight of 210 fruits $/ \mathrm{kg}$ were used in each of the fermentation experiments. The fruits, which were green at the time of harvest, were from the Akhisar region in Manisa, Turkey.

\section{Experimental design}

The 'Domat' cultivar olives were washed, and their bitter compounds were removed by three different methods.

- In the control group, the bitter compounds were removed using tap water. After this pre-treatment, the olives were placed in brine $(4.5 \mathrm{~g} / 100 \mathrm{~mL}$ of $\mathrm{NaCl})$ for the fermentation process.

- In another group, the bitter compounds were removed via lye treatment $(1 \% \mathrm{NaOH})$ (application 1). For this purpose, the olives that were unscratched remained in the lye solution $(1 \% \mathrm{NaOH})$ until penetrated $60 \%$ of the fruit flesh. Then the olives were washed twice a week in tap water, thereby, completely removing the $\mathrm{NaOH}$. Citric acid $(0.5 \mathrm{~g} / 100 \mathrm{~mL})$ was added in the first wash to neu- tralize the lye solution. After this pre-treatment, the olives were placed in brine $(4.5 \mathrm{~g} / 100 \mathrm{~mL}$ of $\mathrm{NaCl})$ for the fermentation process.

- A third group of olives were scratched and left in $\mathrm{CaCl}_{2}$ solution $(1 \mathrm{~g} / 100 \mathrm{~mL})$ for 24 hours. At the end of the 24 hours, the $\mathrm{CaCl}_{2}$ solution was discharded and replaced with brine $(3 \mathrm{~g} / 100 \mathrm{~mL}$ of $\mathrm{NaCl})$. The bitter compounds of these olives were removed by replacing the brine two times a week for 33 days. After this pre-treatment, the olives were placed in brine solution containing the following: $3.5 \mathrm{~g} / 100 \mathrm{~mL}$ of $\mathrm{NaCl}$ (applications 2 and 3), 4.5 $\mathrm{g} / 100 \mathrm{~mL}$ of $\mathrm{NaCl}$ (applications 4 and 5) or $6 \mathrm{~g} / 100 \mathrm{~mL}$ of $\mathrm{NaCl}$ (applications 6 and 7) for the fermentation process.

All the applications were performed in triplicate. The starter cultures Lactobacillus brevis and Pediococcus cerevisiae were added at a $0.2 \%$ concentration to the applications 3, 5 and 7 . These microorganisms were incubated at $30^{\circ} \mathrm{C}$ for 48 hours in an MRS broth. Sugar was added to all of the fermentation brines (1\%). The fermentation experiments were carried out in $5 \mathrm{~L}$ plastic vessels at room temperature $\left(16-22^{\circ} \mathrm{C}\right)$. The olive to brine ratio was approximately $3: 2(\mathrm{w} / \mathrm{w})$. Fermentation was monitored by physical and chemical analyses of samples removed over the course of 90 days (Aktan and Kalkan, 1999; De Castro et al., 2002; Erten, 2000; Montano et al., 2003, Marsilio et al., 2005; Panagou et al., 2002; Sanchez et al., 2001; Tassou et al., 2002). At the end of the storage period, the organoleptic quality of the olives was determined (Panagou $e t$ al., 2002). The experiment was repeated for two consecutive years.

\section{Physical and chemical analyses}

The titratable acidity and salt content of the olive fruits and brine were determined using IOOC titrimetric methods ("**, 1990; Kilıç et al., 1991; Uylaser and Basoğlu, 2011). The amount of reducing sugar was determined as spectrophotometric method using Shimadzu UV-1208 UV-Vis spectrophotometer (Amodioha, 1998). For this purpose, $6 \mathrm{~mL}$ of a dinitrosalicylic acid solution (1 $\mathrm{g}$ dinitrosalicylic acid, $20 \mathrm{~mL}$ of $2 \mathrm{M} \mathrm{NaOH}$ and $20 \mathrm{~g}$ of K-Na tartarate per $100 \mathrm{~mL}$ distilled water) was transferred to a tube. The sample was then clarified using Carrez I and Carrez II solutions, bleached using activated charcoal and filtered. Following this step, $2 \mathrm{~mL}$ of the filtrate was added into the tube. The tube was placed in a boiling water bath for $5 \mathrm{~min}$ and then immediately cooled. The absorbance was read against a blank at $540 \mathrm{~nm}$ and the amount of reducing sugar was calculated from a standard glucose curve that had been prepared previously. The nitrogen content was determined the using Kjeldahl method using the 6.25 for crude protein determination (Matissek et al., 1992; Uylaser and Basoglu, 2011). The moisture and ash contents of the olive fruits were determined according to the methods described by Cemeroğlu (1992). Spectrophotometric determinations of oleuropein and fruit color were performed according to the method described by 
Korukluoğlu (1992); a Schimadzu UV-1208 spectrophotometer was used. The oil content of the olive fruits was determined by Soxhelet extraction using $n$-hexane (Matissek et al., 1992). The analyses were carried out paralles in triplicate for each application.

\section{Organoleptic evaluation}

The organoleptic evaluation was performed by ten panelists using a ten-point scale in which 10 indicated "extreme likeness" and 0 indicated "extreme dislike" ( $\mathrm{Pa}$ nagou et al., 2002). The panelists who participated in the organoleptic analyses were academic personnal from the Susurluk Technical Vocational School of Higher Education, and they had previously been trained in brined olive evaluation criteria.

\section{Results and discussion}

\section{Fruit characteristics}

The results of the physical and chemical analyses of 'Domat' cultivar olives used as raw material are shown in Tab. 1.

Tab. 1. Physical and chemical properties of 'Domat' cultivar olives

\begin{tabular}{ccc}
\hline Years & 1 & 2 \\
\hline Fruit flesh ratio $(\%)$ & 82.66 & 83.07 \\
\hline Stone ratio $(\%)$ & 16.53 & 16.93 \\
\hline Fruit flesh / Stone ratio & 5.00 & 4.89 \\
\hline Number of olive fruit $/ \mathrm{kg}$ & 210 & 136 \\
Moisture $(\mathrm{g} / 100 \mathrm{~g})$ & 65.22 & 68.18 \\
\hline Ash $(\mathrm{g} / 100 \mathrm{~g})$ & 0.34 & 1.25 \\
\hline Oil $(\mathrm{g} / 100 \mathrm{~g})$ & 5.64 & 7.38 \\
\hline Protein $(\mathrm{g} / 100 \mathrm{~g})$ & 1.57 & 1.58 \\
\hline Reducing sugar $(\mathrm{g} / 100 \mathrm{~g})$ & 1.24 & 1.36 \\
\hline Oleuropein $(\mathrm{ABS})$ & 1.12 & 1.14 \\
\hline
\end{tabular}

The results of the physical and chemical analyses of 'Domat' cultivar olives were in agreement with those reported by Canbaş and Fenercioğlu (1989), Özen et al. (1997), Nergiz and Enez (2000), Şahin et al. (2000), Uylaşer et al. (2000), Şahin et al. (2002) and Biricik (2004). However, the 'Domat' cultivar olives in this study had lower oil and moisture contents and contained a larger amount of fruit flesh than did those reported in other studies. The differences might be attributable to annual climatic changes, harvest maturity and farming applications.

Tab. 2. Absorbance values of oleuropein in olives following bitter compound removal

\begin{tabular}{ccc}
\hline \multirow{2}{*}{ De-bittering Methods } & \multicolumn{2}{c}{ Oleuropein Amounts $(\mathrm{ABS})$} \\
\cline { 2 - 3 } & 1. year & 2. year \\
\hline In the brine (By scratching) & $0.026 \pm 0.000$ & $0.279 \pm 0.006$ \\
Using lye $(1 \% \mathrm{NaOH})$ & $0.045 \pm 0.008$ & $0.420 \pm 0.001$ \\
Using tap water & $0.070 \pm 0.001$ & $0.402 \pm 0.002$ \\
\hline
\end{tabular}

The absorbance values of oleuropein after the three bitter compound removal methods are shown in Tab. 2 .

The results showed that the oleuropein level in raw olives reached a desired level following each de-bittering methods. Altough the scratching method was the most effective way to remove (which diffused from the olives to the brine), it plateaued for 33 days. It was observed that the lye treatment was completed in a short period of time. However, the lye treatment negatively affected the nutritional and organoleptic qualities of the olives. The absorbance values at $345 \mathrm{~nm}$ of oleuropein after the fermentation process have been reported to be 0.06-0.09 (Çetin and Pamir, 1980), 0.085-0.087 (İşgöz and Kılıç, 1991), 0.018-0.101 (Korukluoğlu, 1992) and 0.130-0.102 (Biricik, 2004).

\section{Physical, chemical and organoleptic changes during the fermentation process}

The changes of in titratable acidity (as lactic acid) in the brine and olive flesh during the first and second year are shown in Fig. 1 and 2. In three of the experiments (applications 3, 5 and 7), the titratable acidity was attacked on day 14 . The highest titratable acidity values (lactic acid) were $0.46 \mathrm{~g} / 100 \mathrm{~mL}$ and $0.72 \mathrm{~g} / 100 \mathrm{~mL}$ in the first and the second years (application 7), respectively on day 34 . The lowest titratable acidity was $0.19 \mathrm{~g} / 100 \mathrm{~mL}$ in the first year (application 1) and $0.36 \mathrm{~g} / 100 \mathrm{~mL}$ in the second
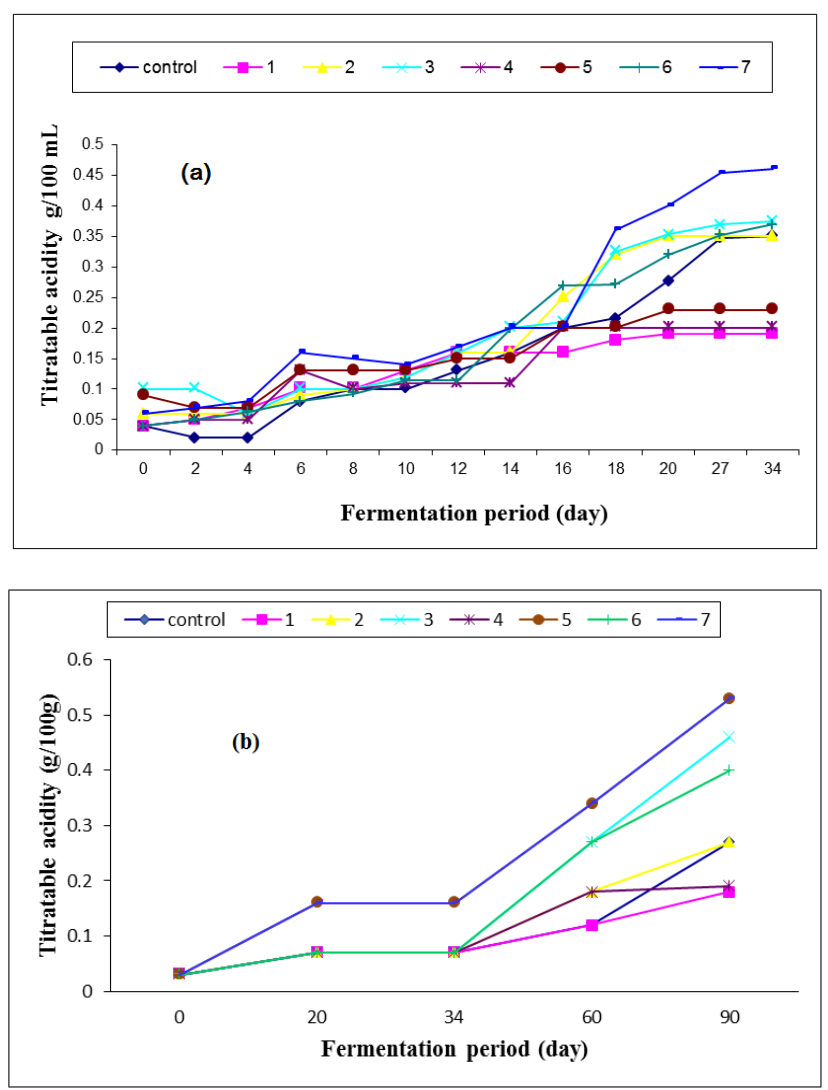

Fig. 1. Change in titratable acidity in the brine (a) and olive flesh (b) during the fermentation process (first year) 

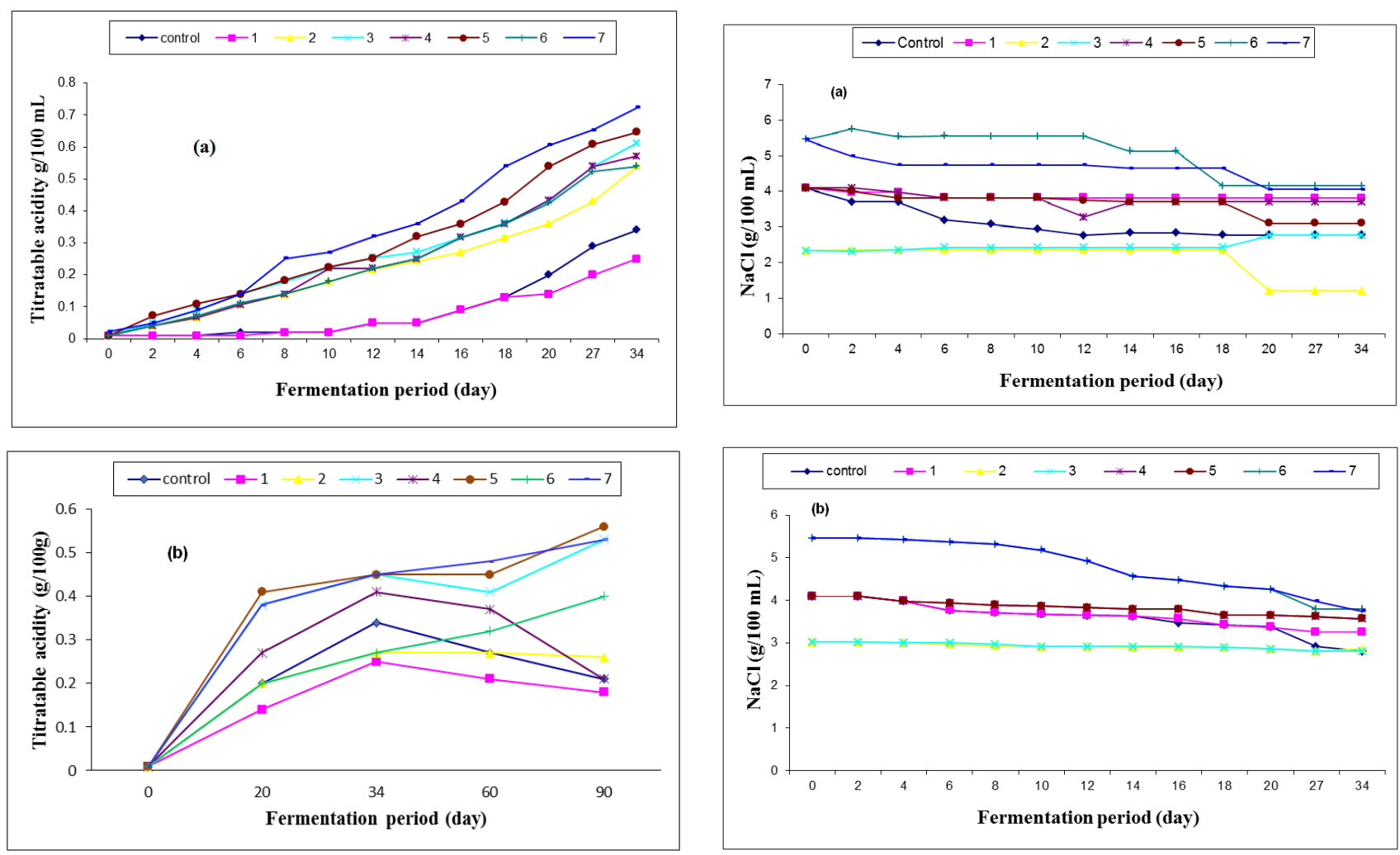

Fig. 2. Change in titratable acidity in the brine (a) and olive flesh (b) during the fermentation process (second year)

year (control group). In the subsequent days of fermentation, the titratable acidity in the brine was higher in applications 3, 5 and 7 containing the starter cultures than in applications 1, 2, 4 and 6 containing no starter cultures. The titratable acidity values were higher in applications 2 , 3, 4, 5, 6 and 7 (with a brine replacement during the pretreatments) than in the control sample (kept in tap water during the bitterness removal) and application 1 (where the lye solution was added during the bitter compounds removal). The titratable acidity of the olive flesh at the end of the fermentation process is shown in Fig. 3.

Fig. 4. Change in the salt content of the brine during fermentation in the first (a) and second (b) year

According to the Turkish Standards (TS 774) $\left(^{* * *}\right.$, 1997), the lowest titratable acidity (lactic acid) is 0.4 $\mathrm{g} / 100 \mathrm{~mL}$. In four samples (applications 3, 5, 6 and 7) the titratable acidity was suitable according to the TS 774 criteria. However, in the control sample and in application 1 , which involved processing in a lye solution during the pre-treatment, the titratable acidity was lower than the TS 774 limits.

The changes in the salt concentration in the brine during the first and second years are shown in Fig. 4. The salt concentrations in the brines during the fermentation pro-

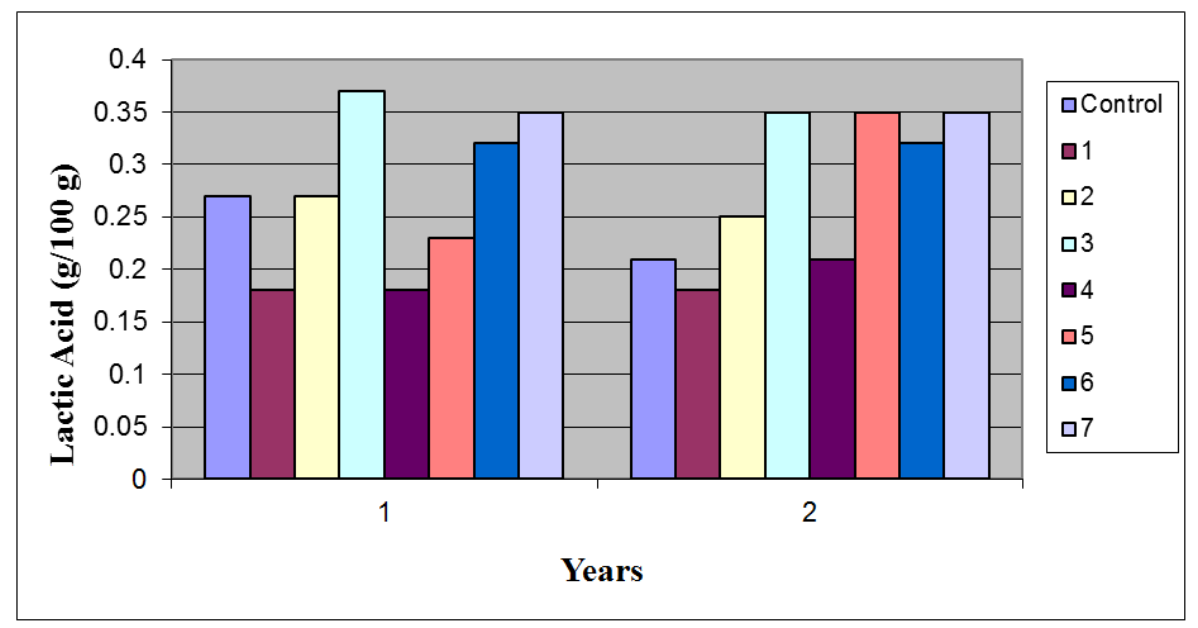

Fig. 3. Increases in the acidity of the fermented and stored products (olive flesh) according to processing method and year 

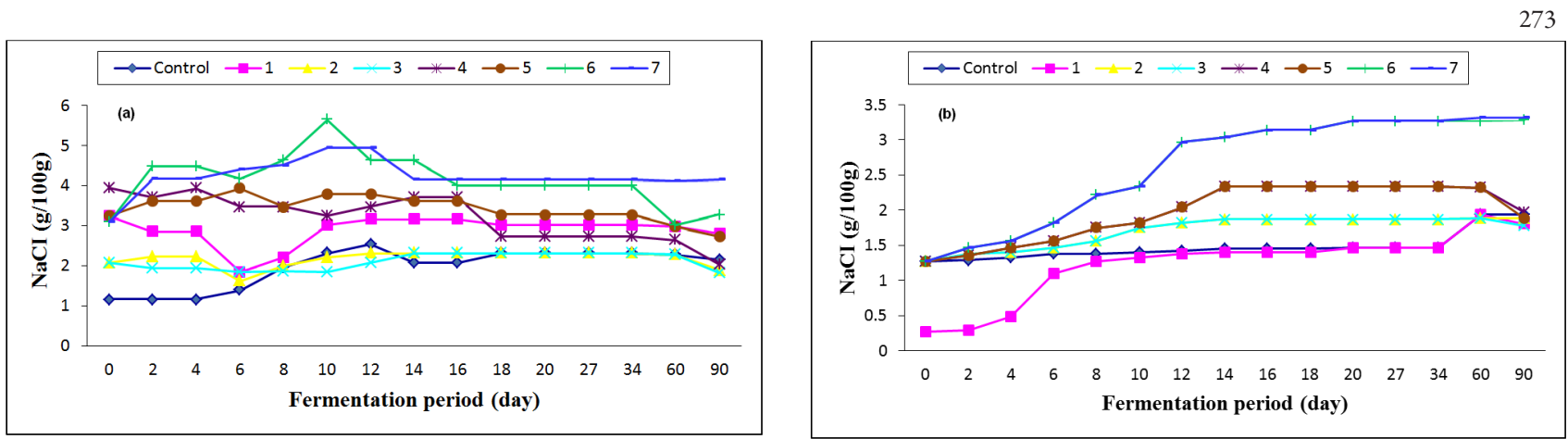

Fig. 5. Change in the salt content of the olive flesh during fermentation in the first (a) and second (b) years

cess ranged from 1.16 to $4.16 \mathrm{~g} / 100 \mathrm{~mL}$ and from 2.80 to $3.80 \mathrm{~g} / 100 \mathrm{~mL}$ in first and second years, respectively. The initial salt concentrations of the brines were gradually reduced during the first week of the fermentation process.

The changes in the salt concentration in the olive flesh during the first and second years are shown in Fig. 5. The salt concentration in the final products, which is important from an organoleptic point of view, was 2.31-4.17 $\mathrm{g} / 100 \mathrm{~mL}$ in the first year and $0.47-3.27 \mathrm{~g} / 100 \mathrm{~mL}$ in the second year. Brine was not added to all the applications after sampling. For this reason, the fruit and the brine were different in each of the applications.

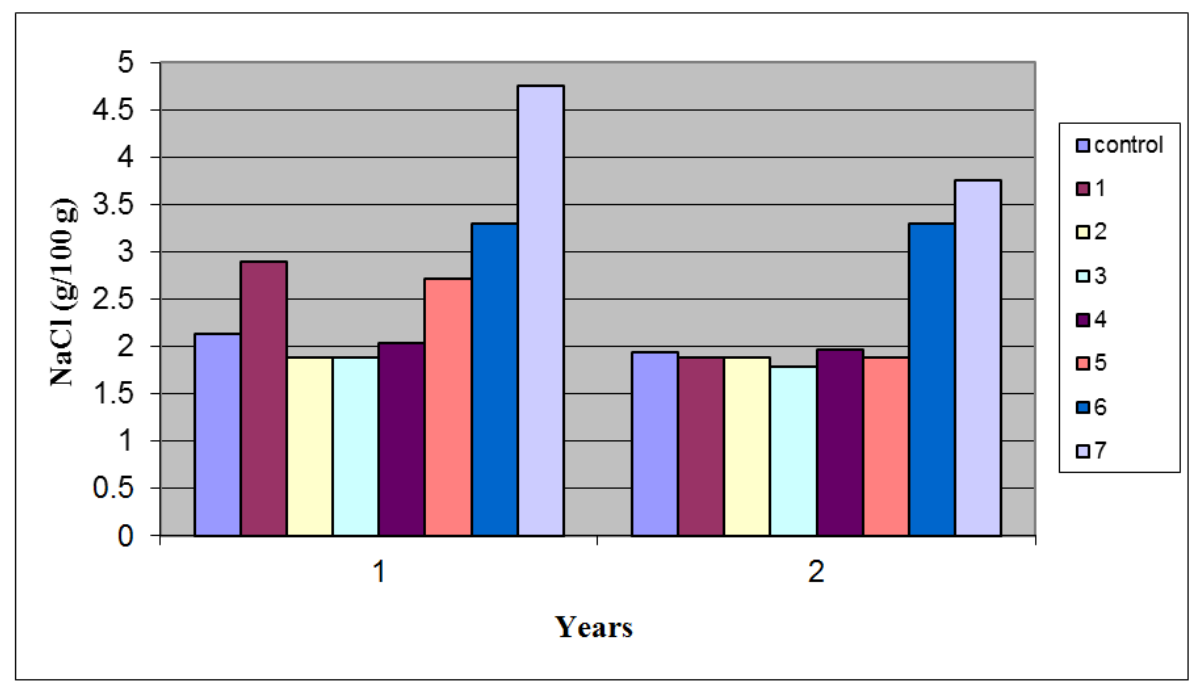

Fig. 6. Change in the salt content of the fermented and stored products (olive flesh) according to processing method and year

Tab. 3. Physico-chemical characteristics of the final products (olive flesh)

\begin{tabular}{cccccc}
\hline Years & Applications & Moisture $(\mathrm{g} / 100 \mathrm{~g})$ & Protein $(\mathrm{g} / 100 \mathrm{~g})$ & Ash $(\mathrm{g} / 100 \mathrm{~g})$ & Oil $(\mathrm{g} / 100 \mathrm{~g})$ \\
\hline \multirow{4}{*}{} & Control & $70.28 \pm 0.000$ & $0.64 \pm 0.000$ & $2.28 \pm 0.000$ & $4.80 \pm 0.000$ \\
& 1 & $67.51 \pm 2.400$ & $0.83 \pm 0.155$ & $3.07 \pm 0.142$ & $6.04 \pm 0.347$ \\
& 2 & $66.40 \pm 1.186$ & $1.07 \pm 0.050$ & $2.00 \pm 0.462$ & $6.02 \pm 0.739$ \\
1 & 3 & $67.94 \pm 0.550$ & $1.19 \pm 0.147$ & $1.89 \pm 0.020$ & $5.41 \pm 0.070$ \\
& 4 & $65.32 \pm 1.264$ & $1.26 \pm 0.107$ & $3.03 \pm 0.146$ & $6.09 \pm 0.603$ \\
& 5 & $66.03 \pm 0.450$ & $1.21 \pm 0.513$ & $2.92 \pm 0.012$ & $6.19 \pm 0.196$ \\
& 6 & $65.92 \pm 1.677$ & $0.97 \pm 0.196$ & $4.80 \pm 1.227$ & $6.26 \pm 0.559$ \\
& 7 & $64.34 \pm 1.290$ & $0.92 \pm 0.215$ & $6.12 \pm 0.290$ & $5.68 \pm 0.539$ \\
\hline \multirow{4}{*}{} & Control & $72.00 \pm 0.000$ & $1.64 \pm 0.000$ & $2.03 \pm 0.000$ & $6.85 \pm 0.000$ \\
& 1 & $68.12 \pm 1.129$ & $1.29 \pm 0.624$ & $2.66 \pm 0.255$ & $6.91 \pm 0.057$ \\
& 2 & $72.13 \pm 1.460$ & $1.13 \pm 0.104$ & $1.97 \pm 0.354$ & $6.86 \pm 0.012$ \\
& 3 & $68.81 \pm 2.580$ & $1.15 \pm 0.188$ & $2.02 \pm 0.162$ & $6.92 \pm 0.060$ \\
& 4 & $70.49 \pm 1.174$ & $1.11 \pm 0.087$ & $2.73 \pm 0.153$ & $7.07 \pm 0.060$ \\
& 5 & $69.91 \pm 2.070$ & $1.16 \pm 0.225$ & $2.60 \pm 0.136$ & $7.53 \pm 0.289$ \\
& 6 & $69.14 \pm 1.126$ & $0.99 \pm 0.153$ & $4.80 \pm 0.040$ & $7.09 \pm 0.083$ \\
& 7 & $70.14 \pm 0.141$ & $0.99 \pm 0.045$ & $4.76 \pm 0.127$ & $7.12 \pm 0.089$ \\
\hline
\end{tabular}


Tab. 4. Mean organoleptic scores of the processed olives in the first (1) and second (2) years

\begin{tabular}{|c|c|c|c|c|c|c|c|c|c|c|c|c|c|}
\hline \multicolumn{14}{|c|}{ Organoleptic score } \\
\hline \multirow[t]{2}{*}{ Applications } & \multirow[t]{2}{*}{ Fermentation $^{\mathrm{a}}$} & \multicolumn{2}{|c|}{ Color } & \multicolumn{2}{|c|}{$\begin{array}{c}\text { Skin } \\
\text { Hardness }\end{array}$} & \multicolumn{2}{|c|}{$\begin{array}{c}\text { Pit } \\
\text { Detachment }\end{array}$} & \multicolumn{2}{|c|}{ Rancidity } & \multicolumn{2}{|c|}{ Saltiness } & \multicolumn{2}{|c|}{$\begin{array}{l}\text { Overall } \\
\text { Quality }\end{array}$} \\
\hline & & 1. & 2. & 1. & 2. & 1. & 2. & 1. & 2. & 1. & 2. & 1. & 2. \\
\hline Control & $\mathrm{N}$ & 5.5 & 3.5 & 8.5 & 7.5 & 2.1 & 1.7 & 5.6 & 6.5 & 4.6 & 2.6 & 6.4 & 5.6 \\
\hline 1 & $\mathrm{~N}$ & 3.5 & 2.5 & 7.4 & 7.7 & 3.2 & 3.5 & 5.1 & 6.5 & 4.2 & 2.2 & 6.1 & 4.1 \\
\hline 2 & $\mathrm{~N}$ & 6.7 & 5.7 & 7.2 & 7.2 & 5.8 & 6.1 & 6.9 & 5.5 & 2.1 & 2.1 & 6.7 & 6.3 \\
\hline 3 & SA & 7.1 & 6.8 & 7.1 & 6.9 & 6.1 & 7.1 & 7.2 & 5.5 & 2.2 & 2.2 & 7.2 & 7.5 \\
\hline 4 & $\mathrm{~N}$ & 8.2 & 7.8 & 8.9 & 8.9 & 7.2 & 7.7 & 6.1 & 6.9 & 1.8 & 1.5 & 8.1 & 8.1 \\
\hline 5 & SA & 8.4 & 8.1 & 8.8 & 8.8 & 8.1 & 8.3 & 6.2 & 7.2 & 1.4 & 1.1 & 8.2 & 8.2 \\
\hline 6 & $\mathrm{~N}$ & 8.4 & 8.5 & 7.9 & 8.8 & 8.5 & 8.8 & 7.8 & 8.8 & 0.2 & 0.2 & 8.1 & 8.4 \\
\hline 7 & SA & 8.7 & 8.8 & 9.1 & 9.2 & 8.9 & 8.9 & 8.1 & 9.1 & 0.6 & 0.6 & 8.9 & 9.1 \\
\hline
\end{tabular}

${ }^{a} \mathrm{~N}$ : Natural SA: Starter culture additional

The consumption of amount of salt negatively affects human health. One of the aims of this study was to obtain high quality products with low salt contents in the brine. The results obtained from this study showed that this goal was met.

The salt concentrations and physico-chemical characteristics of the olives at the end of the fermentation process are shown in Fig. 6 and Tab. 3, respectively.

The organoleptic evaluation results of the olives are shown in Tab. 4. According to the organoleptic evaluation, the highest overall acceptance score was achieved for application 7, followed by applications 5 and 6 . This finding may be attributable to the panelists preference for the salty and bitter taste of traditional processed olives. The score for overall quality and skin hardness were slightly lower for the control group and for application 1. The color scores were lower in application 1 than in the other applications because of the lye pre-treatment. The lye pre-treatment negatively affected the nutritional and organoleptic qualities of the olives. Color stability was negatively affected by this pre-treatment. The olives that were processed using scratching method had a straw color. The results indicated that the olives treated with the lye solution were more sensitive to oxidation and darkened quickly when they were removed from the brine. In all of applications, the best color stability was obtained in the olives that were de-bittered using the scratching method.

\section{Conclusions}

Food processing and preservation methods are not natural. Green olive processing methods include the application of various chemicals $(\mathrm{NaOH}$, citric acid, etc.). These applications reduce the nutritional value of table olives. Organoleptic quality parameters, including color stability, salty taste, eating quality are affected by these pre-treatments. In particular, lye pre-treatment during bitter compound removel negatively affected the organoleptic and nutritional qualities of the olives. Lactic acid is the main product of green olive fermentation. However, pre- treatment with lye solutions or with organic acids (citric acid) prevents real lactic acid fermentation during industrial processes. Real lactic acid fermentation could occur in low-salt brines and during natural green olive production. However, the addition of starter cultures encourages lactic acid fermentation.

The scratching method in low-salt brines may be easily applied in the industry for improving nutritional and sensory qualities.

\section{References}

*** (1990). Table olive. Publications of International Olive and Olive Oil Council. Bravo 10, 28006, Madrid, 83 p.

*** (1997). TS (774) Table olives. Turkish Standards Institute, No: 23153, Ankara, 6-19 p.

${ }^{* * *}$ IOOC (2012). International Olive Oil Council: World table olive figures. Available at: www.internationaloliveoil.org/ estaticos/view/132-worldtable-olive-figures. Accessed 27 November 2012

Aktan N, Kalkan H (1999). Table olive technology. Ege University Press, Bornova, İzmir, 17-23 p.

Amodioha AC (1998). Effect of cultural conditions of the growth and amylolytic enzyme production by Rhizopus Oryzae. Arch. of Phtopathology and Plant Protection 32(1):1-9.

Biricik GF (2004). Composition of olive cultivars grown in economies of scale and suitability of process. University of Uludag, Institute of Science, PhD Thesis (unpublished), $157 \mathrm{p}$.

Canbaş A, Fenercioğlu H (1989). Research on processed of some olive cultivars grown in Adana in green and black brine. Bursa I. International Food Sympo, 4-6 April, Bursa, $242-254 \mathrm{p}$.

Cemeroğlu B (1992). The basic analysis methods in fruit and vegetable processing industry. Biltav publications, Ankara, $41 \mathrm{p}$.

Çetin H, Pamir MH (1980). Research on effect of oleuropein on lactic acid fermentation in black olive brined processing. 
Ankara University, Faculty of Agriculture. Trade Thesis Abstracts 1:392-402.

De Castro A, Montano A, Casado FJ, Sanchez AH, Rejano L (2002). Utilization of Enterococcus casseliflavus and Lactobacillus pentosus as starter cultures for spanish style green olive fermentation. Food Microbiology 19:637-644.

Erten $\mathrm{H}$ (2000). Fermentation of glucose and fructose by Leuconostoc mesenteroides. Turk J Agric For 24:527-532.

Garrido Fernández A, Fernández Díaz MJ, Adams RM (1997). Table olives. Production and processing. London: Chapman \& Hall.

Ghanbari R, Anwar F, Alkharfy KM, Gilani AH, Saari N (2012). Valuable nutrients and functional bioactives in different parts of olive (Olea europaea L.). Internat J Molec Sci 13:3291-3340.

İşgöz B, Kılıç O (1991). Research on quality of filled and unfilled green olive produced from Gemlik and Çelebi olive cultivars. University of Uludag, Institute of Science, Msc Thesis (unpublished), 95p.

Kılıç O, Çopur ÖU, Göktay Ş (1991). Fruit and vegetable processing technology application guide. University of Uludag, Faculty of Agriculture, Lecture Notes:7, 143 p.

Korukluoğlu M (1992). Research on new methods applicable to the production of table olives black olives. University of Uludag, Institute of Science, PhD Thesis (unpublished), $177 \mathrm{p}$.

Marsilio V, Seghetti L, Iannucci E, Russi F, Lanza B, Felicioni M (2005). Use of a lactic acid bacteria starter culture during gren olive (Olea europaea L cv 'Ascolana' tenera) processing. J Sci Food Agric 85:1084-1090.

Matissek R, Schnepel FM, Steiner G (1992). Lebensmittel Analtik. 2. Auflage. Springer Verlag Berlin, 440 p.

Montano A, Sanchez AH, Casado FJ, De CASTRO A, Rejano L (2003). Chemical profile of industrially fermented green olives of different varieties. Food Chemistry 82(2):297302.

Nergiz C, Engez Y (2000). Compositional variation of alive fruit during ripening. Food Chemistry 69:55-59.

Obied HK, Bedgood DR, Prenzler PD, Robards K (2007). Chemical screening of olive biophenol extracts by hyphenated liquid chromatography. Analytica Chimica Acta 603:176-189.

Obied HK, Prenzler PD, Omar SH, Ismael R, Servili M, Esposto S, Taticchi A, Selvaggini R, Urbani S (2012). Pharmacology of olive biophenols. Adv Molec Toxicol 6:195-242.

Özen H, Gönül ŞA, Aktan N, Alkan S, Tetik D (1997). A research on shortening the washing procedure that applied in Spanish Style processing of 'Domat' olive cultivar. TAGEMGY-96-07/01/010 Olive Research Institute Bornova, İzmir, $99 \mathrm{p}$.
Panagou EZ, Tassou CC, Katsaboxakis KZ (2002). Microbiological, physicochemical and organoleptic changes in dry salted olives of Thassos variety stored under different modified atmospheres at 4 and $20^{\circ} \mathrm{C}$. Internat J Food Sci Technol 37:635-641.

Piga A, Gambella F, Vacca V, Agabbio M (2001). Response of three Sardinian olive cultivars to Greek-style processing. Italian J Food Sci 13(1):29-40.

Rodríguez-Gómez F, Bautista-Gallego J, Romero-Gil V, ArroyoLópez FN, Garrido-Fernández A, García-García P (2012). Effects of salt mixtures on Spanish green table olive fermentation performance. LWT-Food Sci Technol 46:56-63

Romero C, Brenes M, Yousfi K, Garcia P, Garcia A, Garrido A (2004). Effect of cultivar and processing method on the contents of polyphenols in table olives. J Agric Food Chem 52:479-484.

Sanchez AH, Rejano L, Montano A, De Castro A (2001). Utilization at high $\mathrm{pH}$ of starter cultures of Lactobacilli for spanish-style green olive fermentation. Internat J Food Microbiol 67:115-122.

Servili M, Selvaggini R, Esposto S, Taticchi A, Montedoro GF, Morozzi G (2004). Health and organoleptic properties of virgin olive oil hydrophilic phenols: agronomic and technological aspects of production that affect their occurrence in the oil. J Chromatography A 1054:113-127.

Şahin I, Korukluoğlu M, Uylaşer V, Göçmen D (2000). Diet olive and olive paste production. Turkey 1st Symposium on Olive Growing, 6-9 June, Bursa, 179-184 p.

Şahin İ, Korukluoğlu M, Gürbüz O (2002). Different cultivar, yeast and lactic starter use in brined black table olive production and effects of some additives on fermentation period and product quality. Turkey $7^{\text {th }}$ Food Engineering Conference, 22-24 May, Ankara, 203-212 p.

Tassou CC, Panagou EZ, Katsaboxakis KZ (2002). Microbiological and physicochemical changes of naturally black olives fermented at different temperatures and $\mathrm{NaCl}$ levels in the brines. Food Microbiol 19:605-615.

Uylaşer V, Korukluoğlu M, Göçmen D, Yıldırım A, Şahin İ (2000). Effect of different cultivars and applications on product quality in manufacturing of green olive. Turkey $1^{\text {st }}$ Symposium on Olive Growing, 6-9 June, Bursa, 220-226 p.

Uylaser V, Tamer CE, İncedayı B, Vural H, Çopur ÖU (2008). The quantitative analysis of some quality criteria of Gemlik variety olives. J Food, Agric Environ 6(3-4):26-30.

Uylaşer V, Başoğlu F (2011). Basic Food Anaylsis. Dora Publishing, $125 \mathrm{p}$. 